\title{
Education and city in the English-language small-format texts: axiological approach
}

\author{
Julia Starostina ${ }^{1 *}$, Marina Cherkunova ${ }^{1}$, and Antonina Kharkovskaya ${ }^{1}$ \\ ${ }^{1}$ Samara National Research University named after S.P. Korolev, Faculty of Philology and \\ Journalism, The Chair of English Philology, Samara, Russia
}

\begin{abstract}
The present research deals with the study of the linguoaxiological plan of small-format texts in the English-language educational discourse. The empirical basis for the analysis included one hundred presentation texts posted on the websites of British urban schools. The study hypothesis is that small-format presentation texts fully reflect the value paradigm formed by contemporary British society concerning secondary education in urban infrastructure. At that, values are interpreted as axiological dominants, verbalized through a system of linguistic markers. The novelty of the approach to the analysis of the linguocultural plan of small-format texts is due to its integrated nature, involving a progressive shift from the level of evaluative linguistic resources to the identification of evaluative micro- and macroconcepts, followed by the subsequent systematization of the obtained data at the level of the relevant axiological dominants associated in the minds of society with the education sector in the context of the urban environment. According to the analysis, the absolute axiological dominant of contemporary education is the student's "Success" interpreted in a broad sense as academic performance, as well as the ability to apply in later life the skills formed in the course of study. The results obtained can be used for further development of linguoaxiological problematics in other discursive areas.
\end{abstract}

Keywords: linguoaxiology, small-format texts, educational discourse, urban infrastructure.

\section{Introduction}

In the present-day world, it is difficult to overestimate the importance of education for young people since it not only opens up employment prospects but also forms a personality, instills a value system and worldviews; in other words, it is one of the key social tools for educating a full-fledged participant in the contemporary urban environment. In this regard, British school education in the context of urban infrastructure is among the most successful in terms of global practices, and the formation of the necessary social and educational vector begins at the stage of familiarizing potential students with information and advertising materials posted on the school website.

\footnotetext{
* Corresponding author: juliatim@mail.ru
} 
The central position on the main page of school websites is traditionally given to smallformat presentation texts. The purpose of these small-format text units is not so much to provide factual information about an educational institution but rather to highlight its competitive advantages. At the same time, reasoning aimed to help determine the choice in favor of a particular educational institution is based on an axiological platform and reflects the value foundations of the urban educational space as an important life sphere in modern society. At that, values are understood as axiological dominants that verbalize urgent directions of social interests. Thus, small-format school presentation texts provide ample opportunities for identifying the hierarchy of key value orientations of modern society in the education sector, since, due to their limited volume, these presentations differ not only in a clear structural organization but also contain an increased concentration of expressive and evaluative language elements that traditionally apply not only to educational services but also to the localization of educational institutions in urban space.

The present study aims at identifying the hierarchy of value orientations in the field of British education in the context of urban infrastructure by analyzing the linguoaxiological plan of small-format presentation texts on the websites of British schools. The range of research tasks includes answering the following questions:

- Which exactly language tools do form the linguoaxiological plan of small-format texts within the framework of educational discourse? What are their qualitative system characteristics?

- What features of an educational institution are the central objects of a positive evaluation attitude and, accordingly, act as evaluation microconcepts?

- What are the axiological dominants of the contemporary educational space? What kind of macroconcepts are they formed by?

The theoretical basis of the research included relevant scientific works on linguoaxiological issues [1-4], and the theory of small-format texts [5-7]. Language assessment, which is an actual object of scientific interest, is usually considered by contemporary researchers from the standpoint of its implementation in a certain discursive space $[8,9]$. At that, linguistic values are analyzed by linguists in terms of universal mental structures $[10,11]$. Within the framework of educational discourse, evaluative lexical units were studied exclusively from the standpoint of their functional orientation [12-15]. This study represents the first attempt to apply a comprehensive linguoaxiological analysis to identify the system of urgent values of modern society in the field of education by analyzing their verbalization tools. Small-format texts are a fruitful material for studying the linguoaxiological discursive component since they clearly show the need to present information in a condensed form, which requires simultaneous involvement of deep mental structures and language skills [16: 62]. Besides, English-language communication practices are often perceived as a model in other linguocultural communities. Due to this, the study of axiological characteristics of English-language text formations seems to be extremely promising from the viewpoint of the subsequent extrapolation of the results obtained to the study of related phenomena based on other linguistic cultures.

\section{Methods}

The empirical basis of the study included one hundred texts containing a brief presentation of the school. The material was selected using a continuous sampling method from current websites of British urban schools. Sample units were united by a common feature of a small format - their volume did not exceed 500 words. During the analysis of the material, the methods of linguistic-stylistic and discursive analysis were used, as well as the method of quantitative calculations, and the interpretive method. 


\section{Results and discussion}

The conducted linguoaxiological analysis has shown that the student's SUCCESS both during school and after graduation is the absolute axiological dominant of contemporary education. This value is represented in all small-format texts of the sample and is based on two axiological macroconcepts: academic excellence and personal development.

The axiological macroconcept of academic excellence is diverse in its content and includes at least five evaluative microconcepts that are approximately equal to each other in terms of both the frequency of mention in small-format presentation texts and the set of language positive-evaluative representations. Thus, the microconcepts of "academic traditions of the school" and "academic reputation of the school", which are components of this macroconcept, are represented at the linguistic level by evaluation phrases such as a proud tradition of academic excellence, rigorous academic program, and keep true to our founder's principles. An equally significant area of positive evaluation is the school's innovations both in terms of teaching methods and technical equipment. Phrases that conceptualize this parameter necessarily contain a positive evaluative adjective, often intensified by the degree of comparison, for example, innovative and outstanding learning environment, incorporate many of the newer strategies, and the latest technological advances. Individualization of training, highly professional teaching staff, and location in the urban infrastructure are also strong arguments in favor of the school and act as an evaluation vector within the framework of the academic excellence concept. They are implemented, among other things, through the combined use of positive evaluation lexical items, such as outstanding individualized teaching, tailored to each individual, and expert guidance.

The second evaluative macroconcept, which is part of the axiological dominant of a student's SUCCESS is the development of the child's personality. In $30 \%$ of small-format presentation texts, it is noted that academic performance is not the only goal of contemporary British education. During the analysis, three evaluation microconcepts were identified, within which the specified value vector was implemented (through a set of positive evaluation markers). First of all, the variety of possible activities contributes to the development of the student's personality. Lexical units that conceptualize the parameter of developing pastime outside of training sessions are phrases like broad variety and extensive opportunities for extracurricular activities. Besides, the upbringing of the moral qualities of students appears as a valuable area of contemporary school education. At the linguistic level, this idea is actualized through the nomination of character qualities that acquire a positive value in the context of a small-format presentation text. This is exemplified by qualities, such as personal development, self-confidence, and tolerance as important qualities for children. An equally important condition for the balanced development of the student's personality is a friendly and safe school environment, which is represented by the evaluation microconcept verbalized through the following phrases: relaxed yet purposeful environment; a safe, vibrant, and friendly environment. The safety of the school environment is also ensured by its integration into the urban infrastructure, which is confirmed by markers reflecting the geographical parameters of the area in which a particular educational institution operates.

In the framework of small-format presentation texts, consistent representation of considered evaluation microconcepts unified by the high academic standards, combined with opportunities for developing personal qualities and implementing individual interests, translates the general axiological dominant of success as the maximal implementation of personal potential, high achievements, and further success in life. Positive evaluative messages that directly verbalize this key value of contemporary education are included as mandatory components in the paradigm of linguoaxiological means of all small-format 
texts of the sample. The following statements, which contain several positive evaluative lexical units of different parts of speech, can serve as examples: each child leaves school equipped to succeed in their lives; reach outstanding academic achievements.

The results obtained in the study are shown in the following diagram:

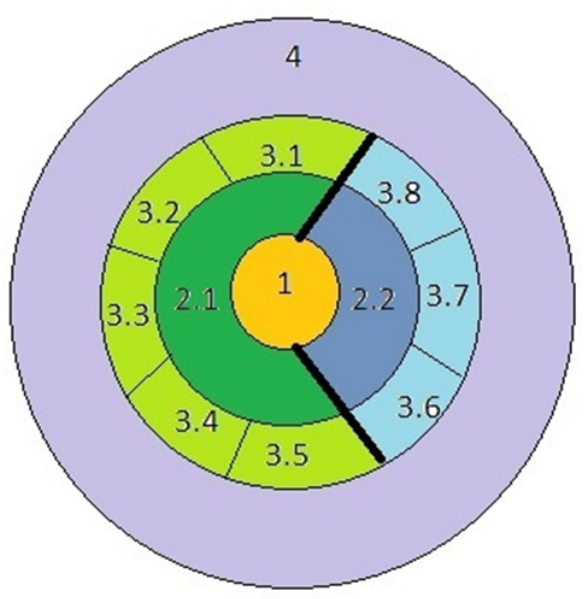

1 - The axiological dominant "Success"

2.1 - Macroconcept "Academic Excellence"

2.2 - Macroconcept "Personal Development"

3.1 - Microconcept "Academic Traditions"

3.2 - Microconcept "Academic Reputation"

3.3 - Microconcept "Innovations"

3.4 - Microconcept "Personalisation"

3.5 - Microconcept "Professional Staff"

3.6 - Microconcept "Variety of Activities"

3.7 - Microconcept "Development of Moral

Qualities"

3.8 - Microconcept "Friendly and Safe School

Environment"

4 - Positive evaluative language tools

Fig. 1. The linguoaxiological paradigm in mini-presentations of British schools.

Thus, the axiological dominant is based on two value macroconcepts, of which each is based, in turn, on a set of evaluative microconcepts, consistently represented in smallformat texts using positive evaluative lexemes. However, in addition to this, the identified axiological dominant also has its own set of linguoaxiological naming units, which proves its primary position in the educational discursive space of the urban infrastructure of Britain.

\section{Conclusion}

A multilevel analysis of the linguoaxiological plan of small-format presentation texts of British schools allows describing adequately the value system of contemporary society in the education sector. The paradigm of evaluative language tools reflects all the concepts that form the value-based conceptual framework of the English-language educational discourse. The key axiological dominant of contemporary education is the student's success in terms of both academic performance and personal development. The macroconcept of academic performance is implemented through a set of six equivalent microconcepts, namely, academic traditions, school reputation, innovation, personalized learning, highly professional teaching staff, and the location of the institution. The macroconcept "Personal development" is based on the combined implementation of three microconcepts: a variety of activities, upbringing of moral qualities, and a safe school environment. At the linguistic level, the components of the value-based educational paradigm are represented by positive evaluative lexical units of different parts of speech that interact within a single evaluative message.

The study of linguoaxiological plan of small-format presentation texts of British schools is of particular importance because it reflects qualitatively values of the contemporary urban education system, and at the same time, allows identifying exactly those linguoaxiological dominants which are actively transmitted to the younger generation, and will determine youth's value orientations in the future. 


\section{References}

1. R. Ağçam, M. Özkan, The Proceedings of the 1st GlobELT Conference on Teaching and Learning English as an Additional Language, 199, 3-11 (August 2015). https://doi.org/10.1016/j.sbspro.2015.07.480

2. T.A. Soldatkina, Bulletin of the Chuvash University, 1, 258-261 (2012)

3. Ye.V. Votintseva, F.G. Fatkullina, Bulletin of the Bashkir University, 20(4), 13521355 (2015)

4. Z.G. Adamova, Moscow State Linguistic University Bulletin. Humanities, 4(833), 42 54 (2020)

5. S.Yu. Lavrova, A.A. Gonchar, Cherepovets State University Bulletin, 3(90), 72-80 (2019). https://doi.org/10.23859/1994-0637-2019-3-90-8

6. O.I. Tayupova, Kommunikativno-pragmaticheskoye var'irovaniye v maloformatnykh prozaicheskikh tekstakh sovremennogo nemetskogo yazyka [Communicativepragmatic variation in small-format prose texts of the modern German language], Thesis (Bashkir State University, Ufa, 2005)

7. A.A. Apostolidi, Linguostylistic characteristics of small-format news media text, Russian word in a multilingual world: Materials of the XIV Congress of International Association of Teachers of Russian Language and Literature, 29 April - 4 May 2019, Astana, Kazakhstan (2019)

8. M.V. Cherkunova, J.S. Starostina, EpSBS 83, 725-732 (2019). https://doi.org/10.15405/epsbs.2020.04.02.85

9. R. El Ayadi, A.R. Smith, Russian Journal of Communication, 3(1), 331-347 (2008). https://doi.org/10.1080/19409419.2008.10756721

10. I.V. Chekulay, O.N. Prokhorova, I.A. Kupriyeva, Belgorod State University Scientific Bulletin. Series: Humanities, 38(1), 80-87 (2019). https://doi.org/10.18413/2075-45742019-38-1-80-87

11. Ye.M. Volf, Funktsional'naya semantika otsenki [Functional semantics of evaluation] (URSS, Moscow 2019)

12. O.N. Isaeva, I.B. Krivchenko, Philological Sciences. Questions of theory and practice, 9, 234-238 (2019). https://doi.org/10.30853/filnauki.2019.9.48

13. T.V. Markelova, M.V. Petrushina, A.A. Savelyeva, SHS Web Conf. 29, 02027 (2016). https://doi.org/10.1051/shsconf/20162902027

14. L.N. Polunina, Izvestia of the Volgograd State Pedagogical University, 60(6), 127-130 (2011)

15. Yu.S. Saraykina, Sovremennyye tendentsii v angloyazychnom obrazovatel'nom diskurse (na materiale serii uchebnykh posobiy "Outcomes") [Modern trends in the English-language educational discourse (based on the series of textbooks “Outcomes”)], Thesis (Samara National Research University, Samara, 2017)

16. A.A. Kharkovskaya, E.V. Ponomarenko, A.V. Radyuk, Training, Language and Culture, 1(1), 62-76 (2017). https://doi.org/10.29366/2017tlc.1.1.4 